\title{
Evaluasi Tarif Berdasarkan Biaya Operasional Kendaraan (BOK) di Terminal Purabaya (Bungurasih) untuk Bus Damri P8
}

\author{
Rozelia Barros ${ }^{1}$, Amrita Winaya ${ }^{2}$, Mutiara Firdausi ${ }^{3}$ \\ 1,2,3 Jurusan Teknik Sipil, Fakultas Teknik Sipil dan Perencanaan, Institut Teknologi Adhi Tama Surabaya \\ Email: $\underline{\text { 1barrosbabo@gmail.com },{ }^{2} \text { dsw.amrita@gmail.com },{ }^{3} \text { mutiara_firdausi89@itats.ac.id }}$,
}

\begin{abstract}
Transportation becomes a vital means for human life as it is used for removing, driving, carrying, or transferring objects from one place to another. Damri Bus serves as a city bus in Surabaya passing through toll and non-toll roads. Damri Bus P8 is one of city buses operating from Purabaya (Bungurasih) Terminal to Perak through toll road. This research aimed at identifying direct and indirect cost components of Damri Bus P8 and adjusting its tariff based on Vehicle Operating Cost. The research method employed the Decree of Transportation Minister No. 89 in 2002. The result of calculation on Vehicle Operating Cost of Damri Bus P8 passing the toll road obtained the tariff IDR $5,881.00$, whereas the actual tariff based on the stipulation of Indonesian Transportation Ministry is IDR 6.000,00. Thus, it could be concluded that the tariff of Damri Bus P8 was appropriate in which price was determined by considering the increasing price of fuel
\end{abstract}

Keywords: Vehicle Operating Cost, Damri P8, freight rate

\section{Pendahuluan}

Angkutan umum merupakan salah satu sarana transportasi untuk mengurangi kemacetan lalu lintas, selain itu juga dapat diharapkan menanggulangi bangkitan dan tarikan perjalanan suatu wilayah. Pelayanan angkutan umum dapat berjalan dengan baik salahsatu caranya adalah dengan menyediakan trayek - trayek pada wilayah tersebut. Pelayanan yang baik dan nyaman diharapkan dapat diberikan kepada konsumen, untuk itu agar didapat pelayanan yang nyaman dan aman perlu ditetapkan tarif yang sesuai [1]. BOK (Biaya Operasional Kendaraan) yang meliputi ban, bahan bakar, pelumas, sopir, atau biaya yang dikeluarkan pada saat armada kendaraan memerlukan perawatan dan penggantian suku cadang kendaraan [2]. Biaya Operasional Kendaraan (BOK) adalah biaya total yang dibutuhkan untuk mengoperasikan sebuah kendaraan [3]. Biaya operasional kendaraan didefinisikan sebagai biaya dari semua faktor-faktor yang terkait dengan pengoperasian satu kendaraan pada kondisi normal untuk satu tujuan tertentu [4].

Komponen Biaya Jasa dan Angkutan Bus Antar Kota Kelas Ekonomi menjadi 2 (dua) yaitu Biaya Langsung dan Biaya Tidak Langsung [5]. Biaya langsung adalah jumlah biaya yang diperhitungkan dalam produksi jasa-jasa angkutan, secara garis besar komponen biaya langsung terdiri dari Biaya Penyusutan atau Depresiasi, Biaya Bunga Modal, Biaya Awak Kendaraan, Biaya BBM, Biaya Pemakaian Ban, Biaya Pemeliharaan/Reparasi Kendaraan, Biaya Retribusi Terminal, Biaya Administrasi, Biaya Asuransi, dan Biaya KIR Kendaraan. Biaya tidak langsung dapat dibagi menjadi beberapa komponen antara lain, Biaya pegawai kantor, Biaya pengelolaan, Biaya administrasi kantor, Biaya listrik, air dan telepon, Biaya perjalanan dinas, Pajak bumi dan bangunan, Biaya izin usaha, Biaya izin trayek, dan Biaya lain-lain/biaya tidak terduga.

Biaya pokok per Microbus $/ \mathrm{km}$ merupakan jumlah dari biaya langsung $(\mathrm{Rp} . / \mathrm{km})$ dan biaya tidak langsung $(\mathrm{Rp} . / \mathrm{km})$. Untuk biaya pokok per Pnp-km diperoleh dari Biaya pokok/bus dibagi dengan jumlah seat, sehingga biaya pokok per penumpang adalah biaya pokok per Pnp-km dikali dengan jarak tempuh.

Terminal Purabaya Bungurasih secara administratif terletak di Kecamatan Waru Kabupaten Sidoarjo. Sistem pengelolaan Terminal Purabaya yaitu dilakukan oleh pemerintah Kota Surabaya. Berdasarkan Perda Kota Surabaya No 12/2014 bahwa terminal ini merupakan tipeA dengan luas lahan 
12 km 2 . Terminal Purabaya melayani Angkutan Kota Antar Propinsi (AKAP), Angkutan Kota Dalam Propinsi (AKDP). Trayek Purabaya - Perak dilayani dengan Bus Damri P8 dengan Rute tanpa melewati tol. Kemudian ditambah armada Bus Damri P8 yang melewati tol. Biaya juga merupakan ukuran tingkat pelayanan, sehingga diperlukan perhitungan biaya yang objektif dan cermat agar dapat dipergunakan sebagai dasar pengambil keputusan. Pengusaha mobil penumpang angkutan umum harus dapat mengontrol biaya yang dikeluarkan guna menentukan pengaruh terhadap usaha dari pengusaha mobil penumpang angkutan umum. Berikut adalah komponen biaya langsung dan biaya tidak langsung.

- Biaya Penyusutan

$$
\text { PerseatKm }=\frac{H K-20 \% N R}{P S T * M S}
$$

- Biaya Bunga Modal

$$
\text { BiayaBungaModal }=\frac{(N+1) *(H K * 75 \% * I)}{2 * P S T * N}
$$

- Biaya Awak Bus Per tahun

$$
\text { BiayaAwakBusPerTahun }=\frac{\text { BiayaAwakBusPerTahun }}{P S T}
$$

- Biaya BBM

$$
\text { BiayaBBM }=\frac{\text { BiayaBBMPerBusPerHari }}{P S T}
$$

- Biaya Ban

$$
\text { BiayaBan }=\frac{\text { BiayaBanPeBus }}{\text { DayaTahanBun }{ }^{*} \text { KapasitasAngkut }}
$$

- Biaya Pemeliharaan

$$
\text { BiayaPemelharaan }=\frac{\text { BiayaServis }}{\text { Dilakukan\&tiapKm* KapasitasAngkut }}
$$

- Biaya Retribusi Terminal

$$
\text { BiayaretribusiTermial }=\frac{\text { PerHariPerBus }}{P S T}
$$

- Biaya STNK

$$
\text { BiayaSTNK }=\frac{H K * \text { PKBPerBusTahun } *(0,5 \% \text { dariHK })}{P S T}
$$

- Biaya Kir Bus

$$
\text { BiayaKirBus }=\frac{\text { BiayaKirPerBus }}{P S T}
$$

- Biaya Asuransi Kendaraan

$$
\text { BiayaAsuransi }=\frac{2,5 \% * H K}{P S T}
$$

- Biaya Izin Trayek

$$
\text { BiayaIzinTrayek }=\frac{\text { BiayaIzinTrayek }}{P S T}
$$

- Tarif Pokok Per Kilometer

$$
\text { TarifPokokPerKilometer }=\frac{B O K}{\text { LoadFactor } * \text { Seat }}
$$

- Tarif 
Tarif $=($ TarifPokokPerKilometer $*$ Jarak $)+10 \%$ Tarif

Keterangan : N = Masa Pinjaman, HK = Harga Kendaraan, PST = Seat Km Per Seat

\section{Metode}

Pada penelitian ini metode yang digunakan untuk menentukan Biaya Operasional Kendaraan (BOK) Bus Damri trayek Bungurasih-Perak adalah berdasarkan Keputusan Menteri Perhubungan No.89 Tahun 2002. Pada penelitian ini metode yang digunakan untuk menentukan Biaya Operasional Kendaraan (BOK) Bus Damri trayek Bungurasih-Perak adalah berdasarkan Keputusan Menteri Perhubungan No.89 Tahun 2002.

Dalam pelaksanaan penelitian ini terdapat 2 data yaitu data primer dan data sekunder. Untuk data primer terdiri dari pendapatan per hari, Jumlah penumpang, BBM, dan Biaya cuci bus. Untuk data sekunder terdiri dari Biaya penyusutan, Biaya awak bus per tahun, Biaya Ban, Servis kecil, Servis Besar, Biaya penambahan oli mesin, Biaya STNK, Biaya kir bus, Biaya asuransi kendaraan, dan Biaya izin trayek. Setelah data - data tersebut diperoleh maka dilakukan analisis Biaya Operasional Kendaraan.

Berdasarkan Keputusan Menteri Perhubungan No.KM 89 Tahun 2002 Analisa BOK (Biaya Operasional Kendaraan), ada beberapa tahap yaitu Karakteristik Kendaraan, Produksi Per Bus dan Biaya Seat Per Bus. Dapat dilihat pada tabel dibawah ini.

Tabel 1. Karakteristik Kendaraan

\begin{tabular}{|l|l|}
\hline \multicolumn{1}{|c|}{ Type } & \multicolumn{1}{c|}{ Bus Damri } \\
\hline Jenis pelayanan & Bus antar kota kelas ekonomi \\
\hline Kapasitas angkut & pnp \\
\hline
\end{tabular}

Tabel 2. Produksi Per Bus

\begin{tabular}{|l|l|}
\hline \multicolumn{1}{|c|}{ Km tempuh per rit } & \multicolumn{1}{c|}{ Km } \\
\hline Frekwensi & Rit \\
\hline Km tempuh per hari & Km \\
\hline Hari operasi per bulan & Hari \\
\hline Hari operasi per tahun & Hari \\
\hline Km-tempuh per bulan & Km tempuh per hari $*$ Km tempuh per bulan $(\mathrm{Km})$ \\
\hline Km-tempuh per tahu & Km tempuh per hari $*$ Km tempuh per tahun $(\mathrm{Km})$ \\
\hline Seat km per rit & Kapasitas angkut $*$ Km tempuh per rit $($ seat $\mathrm{km})$ \\
\hline Seat km per hari & Kapasitas angkut $*$ Km tempuh per hari $($ seat $\mathrm{km})$ \\
\hline Seat km per bulan & Kapasitas angkut $* \mathrm{Km}$-tempuh per bulan $($ seat $\mathrm{km})$ \\
\hline Seat km per tahun $(\mathrm{PST})$ & Kapasitas angkut $* \mathrm{Km}$-tempuh per tahun $($ seat $\mathrm{km})$ \\
\hline
\end{tabular}

Biaya Per Seat Km ada Biaya Langsung dan Biaya tidak langsung. Biaya Langsung ada Biaya Penyusutan, Biaya Bunga Modal, Biaya Awak Bus Per Tahun, Biaya BBM, Biaya Ban, Biaya Pemeliharaan/Reparasi Kendaraan, Biaya Retribusi Terminal, Biaya PKB (STNK), Biaya Kir Bus dan Biaya Asuransi Kendaraan. Biaya Tidak Langsung meliputi Biaya Izin trayek.

\section{Hasil dan Pembahasan}

Data yang diperoleh dari survei primer maupun sekunder selanjutnya diolah untuk menentukan Biaya Operasional Kendaraan (BOK) Bus Damri trayek Bungurasih-Perak. Data primer terdiri atas pendapatan per hari, jumlah penumpang, biaya BBM, dan biaya cuci bus. Sedangkan untuk data sekunder berupa biaya penyusutan, biaya awak bus per bulan, harga kendaraan, biaya ban, biaya pemeliharaan, dan biaya izin trayek. Karakteristik kendaraan yang digunakan pada penelitian ini yaitu type kendaraan adalah bus Damri, jenis pelayanan bus antar kota dengan kapasitas angkut 46 orang.

Tabel 1. Data Primer BOK Bus Damri Bungurasih-Perak

\begin{tabular}{ll}
\hline Pendapatan per hari: & Pendapatan per rit $=\mathrm{Rp} 276.000 ;$ tarif $\mathrm{Rp} 6.000,-$ kapasitas 46 orang \\
\hline Jumlah penumpang & Setiap rit $=46$ orang \\
\hline
\end{tabular}


Biaya BBM

Biaya cuci bus
BBM Solar per hari sebanyak 100 liter, dengan harga Rp 5.150,- per liter Per hari Rp 10.000,-

Tabel 2. Data Sekunder BOK Bus Damri Bungurasih-Perak

\begin{tabular}{ll}
\hline Biaya penyusutan & Masa penyusutan 5 tahun, nilai residu 20\% \\
\hline Biaya awak bus per bulan & Gaji sopir: Rp 3.500.000,- Gaji kondektur: Rp 1.950.000,- \\
\hline Harga kendaraan & Rp 620.000.000,-- \\
\hline Biaya pembelian ban & Rp 2.600.000,-/ban, merek Tubeles \\
\hline Biaya pemeliharaan & $\begin{array}{l}\text { Servis kecil: Rp } 2.500 .000,-/ \text { bulan, Servis besar: Rp 7.000.000,-/6 bulan, } \\
\text { Penambahan oli mesin 17 liter/hari dengan harga Rp 35.000,- }\end{array}$ \\
\hline Biaya izin trayek & Per 6 bulan sekali sebesar Rp 500.000,-- \\
\hline
\end{tabular}

Selanjutnya dilakukan perhitungan terhadap produksi per bus, dengan frekuensi per hari sebanyak 4 rit, hari operasi per bulan 30 hari, hari operasi per tahun 360 hari, dan km tempuh per rit adalah $22,4 \mathrm{~km}$.

Tabel 3. Produksi per Bus

\begin{tabular}{ll}
\hline Km tempuh per hari: & $22,4 \mathrm{~km} \times 4$ rit $=89,6 \mathrm{~km}$ \\
\hline Km tempuh per bulan: & $89,6 \mathrm{~km} \times 30$ hari $=2688 \mathrm{~km}$ \\
\hline Km tempuh per tahun: & $89,6 \mathrm{~km} \times 360$ hari $=8064 \mathrm{~km}$ \\
\hline Seat km per rit: & 46 seat $\times 22,4 \mathrm{~km}=1030,4$ seat $\mathrm{km}$ \\
\hline Seat km per hari: & 46 seat $\times 89,6 \mathrm{~km}=4121,6$ seat $\mathrm{km}$ \\
\hline Seat $\mathrm{km}$ per bulan: & 46 seat $\times 2688 \mathrm{~km}=123648$ seat $\mathrm{km}$ \\
\hline Seat $\mathrm{km}$ per tahun (PST): & 46 seat $\times 32256 \mathrm{~km}=1483776$ seat $\mathrm{km}$ \\
\hline
\end{tabular}

Dari berbagai komponen biaya tersebut kemudian dihitung dan dikategorikan menjadi biaya langsung dan tidak langsung. Rekapitulasi perhitungannya ada pada Tabel 4.

Tabel 4. Rekapitulasi BOK Bus Damri Bungurasih-Perak

\begin{tabular}{ll}
\hline A. Biaya Langsung & $\mathrm{Rp} 66,80 \mathrm{bus} / \mathrm{km}$ \\
\hline 1. Biaya penyusutan & $\mathrm{Rp} 43,67 \mathrm{bus} / \mathrm{km}$ \\
\hline 2. Biaya awak bus per tahun & $\mathrm{Rp} 449,81 \mathrm{bus} / \mathrm{km}$ \\
\hline 3. Biaya BBM & $\mathrm{Rp} 624 \mathrm{bus} / \mathrm{km}$ \\
\hline 5. Biaya ban & $\mathrm{Rp} 10,87 \mathrm{bus} / \mathrm{km}$ \\
\hline 6. Biaya servis kecil & $\mathrm{Rp} 11,71 \mathrm{bus} / \mathrm{km}$ \\
\hline 7. Biaya penambahan oli mesin & $\mathrm{Rp} 577,45 \mathrm{bus} / \mathrm{km}$ \\
\hline 8. Biaya cuci bus & $\mathrm{Rp} 291,15 \mathrm{bus} / \mathrm{km}$ \\
\hline 9. Biaya PKB (STNK) & $\mathrm{Rp} 1,29 \mathrm{bus} / \mathrm{km}$ \\
\hline 10. Biaya kir bus & $\mathrm{Rp} 0,34 \mathrm{bus} / \mathrm{km}$ \\
\hline 11. Biaya asuransi kendaraan & $\mathrm{Rp} 10,45 \mathrm{bus} / \mathrm{km}$ \\
\hline B. Biaya Tidak Langsung & \\
\hline 1. Biaya izin trayek & $\mathrm{Rp} 0,40 \mathrm{bus} / \mathrm{km}$ \\
\hline Jumlah & $\mathrm{Rp} 1921,38 \mathrm{bus} / \mathrm{km}$ \\
\hline
\end{tabular}

Rumus tarif angkutan umum adalah tarif pokok dikalikan jarak rata-rata. Tarif pokok ini sama dengan total biaya pokok yaitu total biaya yang dikeluarkan untuk menghasilkan satu satuan unit produksi jasa angkutan. Km yang ditempuh per tahun sama dengan jarak trayek dikalikan jumlah perjalanan satu hari dikalikan jumlah hari operasi dalam satu bulan dikalikan jumlah bulan dalam satu tahun [6]. Berdasarkan hasil perhitungan Biaya Operasional Kendaraan (BOK) dapat ditentukan tarif yang sesuai dengan BOK tersebut. Load factor yang digunakan adalah 70\% [7]. Perhitungannya sebagai berikut:

$$
\begin{aligned}
\text { Tarif pokok per kilometer } & =\frac{B O K}{\text { load factor } \times \text { seat }} \\
& =\frac{1921,38}{0,7 \times 46}
\end{aligned}
$$




$$
=\operatorname{Rp} 59,67
$$

Tarif angkutan umum penumpang merupakan hasil perkalian antara tarif pokok dan jarak dalam kilometer untuk rata-rata satu kali perjalanan, ditambah dengan $10 \%$. Persentase $10 \%$ adalah sebagai besaran keuntungan pengoperasian bus Damri ini [8]. Perhitungannya sebagai berikut:

$$
\begin{aligned}
\text { Tarif berdasarkan BOK } & =(\text { tarif pokok x jarak })+10 \%(\text { tarif pokok } x \text { jarak }) \\
& =(\operatorname{Rp} 59,67 \times 89,6)+10 \%(\text { tarif pokok } \times \text { jarak }) \\
& =\operatorname{Rp} 5346,4+\operatorname{Rp} \operatorname{Rp} 534,6 \\
& =\operatorname{Rp} 5881,-
\end{aligned}
$$

Tarif sebesar Rp 5881,- sesuai hasil perhitungan diatas adalah tarif untuk setiap penumpang. Apabila dilakukan pembulatan hasilnya adalah $\mathrm{Rp} 6000$,- per penumpang.

\section{Kesimpulan}

Dari hasil perhitungan dan pengolahan data untuk BOK Bus Damri trayek Bungurasih-Perak, dapat diambil kesimpulan sebagai berikut:

1. Nilai BOK Bus Damri trayek Bungurasih-Perak sebesar Rp 1921,38 bus/km, dengan tarif berdasarkan BOK adalah Rp 6000,-. Dalam satu hari beroperasi, bus Damri trayek BungurasihPerak memperoleh pendapatan sebesar Rp 1.104.000,-

2. Berdasarkan hasil evaluasi tarif menurut BOK dihasilkan tarif sebesar Rp 5881,- per penumpang. Nilai tarif ini sesuai dengan besarnya tarif yang berlaku pada bus Damri trayek Bungurasih-Perak saat dilakukan penelitian yaitu Rp 6000,- per penumpang.

\section{Referensi}

[1] J. Pandia, R. M. Simamora, "Evaluasi Tarif Bus Antar Kota Dalam Propinsi (AKDP) Berdasarkan Biaya Operasional Kendaraan Trayek Medan-Doloksanggul," Universitas Sumatera Utara.

[2] E. Mulyati, A. I. Alif, "Perencanaan Tarif Ideal Pengiriman Barang Berdasarkan Metode Perhitungan Biaya Operasional Kendaraan (BOK)," Jurnal Ilmiah Teknik Industri., vol. 12, no. 2, 2013.

[3] T. K. Sukwanti, "Kajian Dampak Perubahan Biaya Operasional Kendaraan (BOK) Akibat Pengalihan Arus Lalu Lintas Dari Ruas Jalan Cadas Pangeran ke Jalur Alternatif," Jurnal Perencanaan Wilayah dan Kota., vol. 23, no. 1, 2012.

[4] Z. Ramadhan, "Analisis Perhitungan dan Perbandingan Biaya Operasional Kendaraan (BOK) Bus Rapid Transit (BRT) Transmusi Jenis Mercedes Benz OH-1521 dan Hino RK8-235 (Studi Kasus: Koridor 1 Terminal Alang-alang Lebar - Terminal Ampera," Jurnal Teknik Sipil dan Lingkungan., vol. 2, no. 1, 2014.

[5] Keputusan Menteri Perhubungan NO.KM 89, "Mekanisme penetapan tarif dan formula perhitungan biaya pokok angkutan penumpang dengan mobil bus umum antara kota", 2002.

[6] S. Arum, Samin, "Analisa Tarif Angkutan Umum Berdasarkan Biaya Operasional Kendaraan, ATP, dan WTP," Media Teknik Sipil., vol. 12, No. 2. 2014.

[7] J. H. Frans, Y. A. Messah, N. T. Issu, "Kajian Tarif Angkutan Umum Berdasarkan Biaya Operasional Kendaraan (BOK), Ability To Pay (ATP), dan Willingness To Pay (WTP) di Kabupaten TTS," Jurnal Teknik Sipil., vol. V, no. 2, 2016.

[8] S. Walsen, "Kajian Biaya Operasional Kendaraan Umum Jalur Terminal Mardika-Air Salobar di Kota Ambon," Jurnal Teknik Sipil., vol. III, no. 1, 2014. 